\title{
Viruses associated with chlorotic rosette and green rosette diseases of groundnut in Nigeria*
}

\author{
BY D. V. R. REDDY $\dagger$, A. F. MURANT $\ddagger$, G. H. DUNCAN, \\ Scottish Crop Research Institute, Invergowrie, Dundee DD2 SDA
}

O. A. ANSA,

Institute for Agricultural Research, Samaru, Ahmadu Bello University, PMB 1044, Zaria, Nigeria,

J. W. DEMSKI AND C. W. KUHN,

Department of Plant Pathology. University of Georgia College of Agriculture, Athens. Georgia 30602, USA

(Accepted I March 1985)

SUMMARY

Groundnut (Arachis hypogaea) plants from Nigeria with chlorotic rosette disease contained a manually transmissible virus, considered to be a strain of groundnut rosette virus (GRV(C)). GRV(C) infected nine out of 32 species in three out of nine families. It caused local lesions without systemic infection in Chenopodium amaranticolor, $C$. murale and $C$. quinoa, and systemic symptoms in Glycine max, Nicotiana benthamiana, $N$. clevelandii and Phaseolus vulgaris as well as in groundnut. Some 'rosette-resistant' groundnut lines were also infected. GRV(C) was transmitted by Aphis craccivora, but only from groundnut plants that were also infected with an aphid-transmissible second virus, which was not manually transmissible and was considered to be groundnut rosette assistor virus (GRAV). Plants infected with GRAV contained isometric particles $c .25 \mathrm{~nm}$ in diameter which were detectable by immunosorbent electron microscopy on grids coated with antisera to several luteoviruses, especially with antisera to bean leaf roll, potato leafroll and beet western yellows viruses. No virus-like particles were observed in extracts from plants infected with GRV(C) alone.

A single groundnut plant obtained from Nigeria with symptoms of green rosette contained luteovirus particles, presumed to be of GRAV, and yielded a manually transmissible virus that induced symptoms similar to those of GRV(C) in $C$. amaranticolor but gave only mild or symptomless infection of $N$. benthamiana and $N$. clevelandii. It was considered to be a strain of GRV and designated $\operatorname{GRV}(G)$.

\section{INTRODUCTION}

Groundnut rosette disease, first reported by Zimmermann (1907), is recognised as the most important virus disease of groundnut (Arachis hypogaea) in Africa south of the Sahara, including Madagascar. Affected groundnut plants contain two viruses, one of which, groundnut

"Submitted as Journal Article No. 461 by the International Crops Research Institute for the Semi-Arid Tropics. Supported in part by the Peanut Collaborative Research Support Program U.S. Aid Grant No. DAN-4048-G.SS2065.00.

tPermanent address: International Crops Research Institute for the Semi-Arid Tropics, Patancheru PO. Andhra Pradesh 502 324, India.

$\$$ To whom requests for reprints should be addressed.

(C) 1985 Association of Applied Biologists 
rosette virus (GRV), is the major or only cause of symptoms in groundnut but is dependent on the other, groundnut rosette assistor virus (GRAV), for transmission by aphids (Okusanya \& Watson, 1966; Hull \& Adams, 1968; Dubern, 1980). The vector is Aphis craccivora (Storey \& Bottomley, 1928) and the virus/vector relations are of the persistent type (Storey \& Ryland, 1955). GRV is transmissible by mechanical inoculation but GRAV is not. The symptoms in groundnut are variable (Hayes, 1932; Storey \& Ryland, 1957: Okusanya \& Watson, 1966; Hull \& Adams, 1968) but are of two major types known as 'chlorotic rosette' and 'green rosette' (Hayes, 1932; Hull \& Adams, 1968; Gibbons, 1977). Isolates of GRV from plants with these two kinds of symptom are referred to here as GRV(C) and GRV(G) respectively. Recently GRAV has been shown to be a luteovirus serologically related to barley yellow dwarf, beet western yellows, bean leaf roll and potato leafroll viruses (Casper et al., 1983). The nature of GRV is not known.

This paper reports preliminary studies, mostly conducted during the period November 1983 - April 1984, to investigate the host range and biological properties of virus isolates from Nigeria obtained from groundnuts with chlorotic rosette and green rosette symptoms. Investigations on the partial purification of GRV(C) and on the nucleic acids associated with chlorotic and green forms of groundnut rosette disease are described in an accompanying paper (Reddy et al., 1985).

\section{MATERIALS AND METHODS}

Test plants. Groundnuts and herbaceous test plants were grown in a screened glasshouse at $25^{\circ} \mathrm{C}$ with supplementary illumination for $18 \mathrm{~h}$ per day from sodium or mercury vapour lamps. Light intensities ranged from approx. 20 to 60 microeinsteins $\mathrm{m}^{-2} \mathrm{~s}^{-1}$.

Virus sources. Twenty-two groundnut plants with chlorotic rosette symptoms and one with green rosette symptoms were brought from Samaru, Nigeria, to the Scottish Crop Research Institute under licence from the Department of Agriculture for Scotland.

Manual transmission. A number of buffers, at a range of molarities and $\mathrm{pH}$ values, were compared for use in manual inoculations. Unless otherwise stated, leaf extracts for use as inoculum were made in $0.01 \mathrm{M}$ tris $-\mathrm{HCl}, \mathrm{pH} 8.0$, containing $0.02 \mathrm{M}$ sodium sulphite and 1 g/litre Mg-bentonite (Dunn \& Hitchborn, 1965).

Aphid transmission. A culture of Aphis craccivora was obtained from Samaru, Nigeria, under licence from the Department of Agriculture for Scotland. Colonies were established from nymphs newly born on healthy plants. Aphid cultures were maintained on groundnut or Vicia faba kept at $25^{\circ} \mathrm{C}$ and illuminated continuously. In transmission experiments the aphids were allowed acquisition access periods of 1 day and inoculation access periods of 2 days. They were then killed by fumigation with nicotine.

Antisera. Antisera to the following viruses, with their quoted homologous titres in parentheses (in gel-diffusion tests unless otherwise stated), were kindly supplied by the workers named; bean leaf roll virus (BLRV) (1/256), J. W. Ashby; beet mild yellowing virus (BMYV) (1/256), D. A. Govier; beet western yellows virus (BWYV) $(1 / 625$ in infectivity neutralisation tests), J. E. Duffus; potato leafroll virus (PLRV), antiserum IBM-4 (1/4000), I. Majewicz; subterranean clover red leaf virus (SCRLV), strain NSW (1/1024), P. M. Waterhouse; SCRLV, strain TAS (1/1024), P. M. Waterhouse; tobacco necrotic dwarf virus (TNDV) (1/1024), S. Kubo. The following antisera were from the Scottish Crop Research Institute collection: PLRV antiserum G (1/1024), carrot red leaf virus (CRLV) (1/2048).

Electron microscopy. Leaf extracts for electron microscopy were made by grinding petiole or midrib tissue in $0.01 \mathrm{M}$ phosphate buffer, $\mathrm{pH} 7.5$, containing $0.02 \mathrm{M}$ sodium sulphite using the 'micromortar' technique of Duncan \& Roberts (1981). Immunosorbent electron microscopy (ISEM) was performed as described by Roberts \& Harrison (1979). Antisera were used at a dilution of $1 / 500$ and samples were stained in uranyl formate/sodium hydroxide, 
pH 4.8 (I. M. Roberts, in Barnett \& Murant, 1970). Grids were examined either in a Philips $301 \mathrm{G}$ or in a Jeol $100 \mathrm{~S}$ electron micros:ope. Estimates of the number of particles $/ 1000 \mu \mathrm{m}^{2}$ of grid were made by the method of Roberts (1980).

\section{RESULTS}

\section{Mechanical transmission of virus isolates from chlorotic rosette-diseased groundnuts}

Extracts were made from each of the 22 groundnut plants imported from Nigeria with chlorotic rosette disease. The extracts, in $0.02 \mathrm{M}$ phosphate buffer, $\mathrm{pH} 8.0$, containing 1 $\mathrm{g} /$ litre $\mathrm{Mg}$-bentonite were each rubbed on to corundum-dusted leaves of 10 groundnut (cv. Robut 33-1) and two Nicotiana clevelandii plants. Two of the extracts failed to induce symptoms in any of the test plants. Three of the extracts induced a reaction characteristic of cowpea mild mottle virus in the groundnut seedlings and this identification was confirmed by electron microscopy and by the reactions of soybean and Chenopodium quinoa. These test plants and the three original groundnut plants were all destroyed by autoclaving. The remaining 17 extracts induced darkening and downcurling of the leaves of $N$. clevelandii after 5 wk. These isolates also induced chlorotic rosette symptoms in groundnut test seedlings, although onfy after about $10 \mathrm{wk}$ under winter glasshouse conditions in Scotland. They were therefore considered to be $\operatorname{GRV}(\mathrm{C})$.

Six of the isolates that infected $N$. clevelandii were examined further. All were free from cowpea mild mottle, peanut clump, peanut mottle and tomato spotted wilt viruses, as shown by the response obtained when extracts from $N$. clevelandii were inoculated to four plants each of Chenopodium amaranticolor, C. quinoa, Phaseolus vulgaris (cv. Topcrop) and groundnut (cv. Robut 33-1).

Table 1. Detection of isometric virus particles in extracts ${ }^{*}$ of chlorotic rosette-diseased groundnut by immunosorbent electron microscopy on grids coated with antisera to various luteoviruses

No. particles $/ 1000 \mu \mathrm{m}^{2}$ area of grid

$\begin{array}{lcc}\text { Antiserum } & \text { Expt I } & \text { Expt } \\ \text { BLRV } & 2613 & 622 \\ \text { PLRV-G } & 1653 & 280 \\ \text { PLRV-IBM 4 } & - & 533 \\ \text { BWYV } & 773 & 107 \\ \text { BMYV } & 106 & 32 \\ \text { TNDV } & - & 85 \\ \text { SCRLV-TAS } & - & 21 \\ \text { SCRLV-NSW } & - & 0 \\ \text { CRLV } & - & 0 \\ \text { Normal serum } & 0 & 0 \\ \text { None (carbon control) } & 53 & 0 \\ & \\ \text { - Groundnut leaf mid-rib tissue was ground with Carborundum } \\ \text { in a small volume of } 0.06 \text { M phosphate buffer, } 0.02 \mathrm{M} \text { sodium } \\ \text { sulphite, pH 7.5, and the extract then centrifuged for } 5 \text { min at } \\ \text { 8000 g. } \\ \text { - test not done }\end{array}$

\section{Electron microscopy of leaf extracts of groundnut with chlorotic rosette disease}

No virus-like particles were observed when extracts from six of the groundnut plants that had yielded GRV(C) were examined by conventional electron microscopy. Three of the 
plants, however, were found to contain isometric particles c. $25 \mathrm{~nm}$ in diameter (Fig. 1) when the extracts were examined by ISEM on grids coated with antibody to various luteoviruses. Table 1 shows that numerous particles were observed on grids coated with antisera to BLRV, PLRV and BWYV, but grids coated with antisera to BMYV, SCRLV-TAS and TNDV trapped fewer particles. No particles were found on grids coated with antiserum to CRLV or SCRLV-NSW.

These observations suggested that, although all six groundnut plants contained GRV(C), only three of them also contained GRAV, which has been reported to react with antisera to luteoviruses (Casper et al., 1983).

\section{Aphid transmission experiments}

Adult Aphis craccivora were allowed to feed for 2 days on the six groundnut plants mentioned in the preceding section and then transferred in groups of 10 for an inoculation access period of 2 days on young groundnut (cv. Robut 33-1) seedlings. These plants were observed for chlorotic rosette symptoms and tested by manual inoculation of sap to $N$. clevelandii for the presence of GRV(C) and by ISEM for the presence of the luteovirus. The aphids transmitted GRV(C) together with the luteovirus from all three of the groundnut plants containing both viruses. In contrast, the aphids transmitted neither of the viruses from the three plants in which no luteovirus particles had been found by electron microscopy. These results confirm the observations of Hull \& Adams (1968) that transmission of GRV(C) by aphids is dependent on the presence in the source plants of a helper virus (GRAV) and supported the view that the luteovirus particles found by ISEM were those of GRAV.

\section{Table 2. Transmission of GRAV and $G R V(C)$ from doubly infected source plants by} Aphis craccivora*

$\begin{array}{cccccc}\text { Expt } & \text { Source } & \text { No. groundnut test seedlings infected with } \\ \text { no. } & \text { plant } & \begin{array}{c}\text { GRAV } \\ \text { alone }\end{array} & \begin{array}{c}\text { GRAV } \\ \text { GRV (C) }\end{array} & \begin{array}{c}\text { GRV (C) } \\ \text { alone }\end{array} & \begin{array}{c}\text { Nether } \\ \text { virus }\end{array} \\ 1 & \text { Groundnut } & 0 & 4 & 4 & 8 \\ 2 & \text { Groundnut } & 1 & 3 & 6 & 5 \\ 3 & \text { Soybean } & 0 & 2 & 2 & 2\end{array}$

\footnotetext{
- Acquisition access time 2 days; inoculation access time 1 day; two aphids per test plant. † Presence of GRAV was detected by ISEM on grids coated with antiscrum to BLRV; presence of GRV(C) was detected by manual inoculation to two $C$. amaranticolor and four N. clevelandii.
}

In attempts to separate GRAV from GRV(C), three aphid transmission experiments were done with small numbers of aphids/test plant (Table 2). Pure cultures of both viruses were obtained but the experiments suggested that, at least under the conditions prevailing in winter in Scotland, GRV(C) is easier to separate from the mixture in this way than is GRAV.

\section{Host range}

Plants of 32 species in nine families were inoculated manually with inoculum prepared from GRV(C)-infected $N$. clevelandii with severe systemic symptoms. At least six plants of each species were inoculated. After $3 \mathrm{wk}$, inoculated and subsequently produced leaves were tested for infection by return inoculation to groundnut or $N$. clevelandii. The virus was detected in inoculated plants of the following species. 


\section{CHENOPODIACEAE}

Chenopodium amaranticolor. Chlorotic local lesions c. $1 \mathrm{~mm}$ in diameter (Fig. 2) visible 4-5 days after inoculation but not increasing in size subsequently. No systemic infection. Lesions were not observed during the period late November to early March.

C. murale. Reacted like C. amaranticolor but lesions (Fig. 3) appeared about 7-10 days after inoculation.

C. quinoa. Reacted like C. amaranticolor but lesions (Fig. 4) were fewer and about $2 \mathrm{~mm}$ in diameter; about $2 \mathrm{wk}$ after inoculation they developed straw-coloured centres with brown margins.

\section{LEGUMINOSAE}

Arachis hypogaea (groundnut), cvs Robut 33-1 and Samaru 38.

The initial symptom, which appeared 10-14 days after inoculation, was systemic veinal chlorosis. Typical chlorotic rosette symptoms (younger leaflets showing bright yellow symptoms and older leaflets showing green islands followed by severe stunting) did not usually appear until about $10 \mathrm{wk}$ after inoculation. Usually fewer than $50 \%$ of the inoculated plants showed typical rosette symptoms. Groundnut plants grew very slowly during winter in Scotland and the long interval before typical symptoms developed was possibly a result of the relatively low light intensities in the glasshouse, despite supplementary illumination.

Glycine max (soybean) cv. CNS. Systemic mild chlorotic mottle without obvious stunting.

Phaseolus vulgaris (French bean) cvs The Prince, Topcrop, Double White and local Indian cultivars. Mild systemic chlorosis after 7-14 days without obvious stunting.

\section{SOLANACEAE}

Nicotiana benthamiana. Chlorosis and curling of systemically infected leaves followed by puckering and downward leaf rolling (Fig. 7). The plants were slightly stunted.

$N$. clevelandii. The most infective inocula, especially those from $N$. benthamiana or $N$. clevelandii, induced a few necrotic rings $2-4 \mathrm{~mm}$ in diameter (Fig. 5) in inoculated leaves within 3-4 days and systemic symptoms after 1 wk. Newly formed leaves became curled and leaves produced subsequently were puckered and distorted, frequently showing necrotic vein etching. The plants were usually severely stunted (Fig. 6). With dilute inocula, especially those made directly from groundnut, no local lesions were observed and systemic symptoms appeared $2 \mathrm{wk}$ or more after inoculation as a darkening and slight downward rolling of the leaves; typical symptoms appeared on the upper leaves up to 1 month after inoculation.

$N$. rustica. No symptoms were observed but the virus was recovered from upper uninoculated leaves by return inoculation to $N$. clevelandii.

The following species were not infected:

AMARANTHACEAE: Gomphrena globosa; APOCYNACEAE: Vinca rosea; COMPOSITAE: Zinnia elegans; CUCURBITACEAE: Cucurbita pepo (cv. Eyes); LEGUMINOSAE: Canavalia ensiformis, Cyamopsis tetragonoloba, Dolichos biflorus, D. lablab, Lathyrus odoratus, Pisum sativum (cvs Onward, Little Marvel), Phaseolus aureus, P. vulgaris (cvs Black Turtle Soup, Bountiful, Great Northern, Pinto, Redland Green Leaf, Wibusa), Vicia faba (cv. Sutton), Vigna unguiculata ssp. cylindrica (cv. EC33830), V. unguiculata ssp. unguiculata (cvs C-152, Moski), V. unguiculata ssp. sinensis (cv. 353) and Voandzeia subterranea; MALVACEAE: Hibiscus esculentus; SOLANACEAE: Datura stramonium. Nicotiana glutinosa. N. tabacum (cvs White Burley, Samsun NN) and Physalis foridana; UMBELLIFERAE: Anthriscus cerefolium, Coriandrum sativum.

Plants of groundnut, soybean (cv. CNS) and Nicotiana clevelandii inoculated by means of aphids (Aphis craccivora) from groundnut plants with chlorotic rosette developed symptoms similar to those produced following manual inoculation, and $G R V(C)$ was recovered from these plants by manual inoculation to $C$. amaranticolor and $N$. clevelandii. 


\section{Tests on rosette-resistant groundnut germplasm}

Several rosette-resistant cultivars have been released in East and West Africa (Gibbons. 1977). They are regarded as resistant because they do not show obvious rosette disease symptoms in the field and because the aphid vector is unable to recover virus from them. Eight plants of each of five resistant germplasm lines and four susceptible cultivars were inoculated manually with a buffer extract from $N$. clevelandii leaves infected with GRV(C). After $4 \mathrm{wk}$, the groundnuts were tested individually by grinding young leaflets in buffer and inoculating the extracts to $N$. clevelandii. Table 3 shows that two of the 'resistant' lines became infected with GRV(C) although three others did not.

Table 3. Response of groundnut germplasm lines to manual inoculation with $G R V(C)$

\begin{tabular}{|c|c|c|}
\hline $\begin{array}{c}\text { Groundnut } \\
\text { germplasm line }\end{array}$ & $\begin{array}{l}\text { Field resporise } \\
\text { to chlorotic } \\
\text { rosette disease }\end{array}$ & $\begin{array}{l}\text { No. groundnut plants } \\
\text { infected/no. inoculated* }\end{array}$ \\
\hline Robut 33-1 & Susceptible & $7 / 8$ \\
\hline TMV-2 & Susceptible & $7 / 8$ \\
\hline MK-374 & Susceptible & $6 / 8$ \\
\hline SP-205 & Susceptible & $6 / 8$ \\
\hline RMP-12 & Resistant & $0 / 8$ \\
\hline RMP-89 & Resistant & $4 / 8$ \\
\hline RMP-91 & Resistant & $0 / 8$ \\
\hline RMP-192 & Resistant & $4 / 8$ \\
\hline $48-15 \mathrm{~A}$ & Resistant & $0 / 8$ \\
\hline
\end{tabular}

Tests on groundnut with green rosette symptoms

Leaf extracts from a single field-infected groundnut plant showing green rosette symptoms were examined on grids coated with antiserum to BLRV; the extracts contained luteovirus particles resembling those of GRAV.

Adult Aphis craccivora were allowed to feed for 3 days on this plant and were then transferred (10 aphids/plant) to nine groundnut (cv. Robut 33-1) seedlings for inoculation access feeds of 2 days. After 3 wk one of the seedlings developed symptoms of green rosette but extracts from it contained no luteovirus particles. Another seedling showed less obvious symptoms but contained numerous luteovirus particles.

When buffer extracts from the seedling with green rosette symptoms were rubbed on herbaceous test plants a virus was recovered which gave local lesions indistinguishable from those of GRV(C) in inoculated leaves of Chenopodium amaranticolor but gave only symptomless systemic infection or extremely mild systemic mottle in Nicotiana benthamiana and $N$. clevelandii. This remained true even after six passages through $N$. benthamiana.

\section{DISCUSSION}

Our studies on groundnut plants from Nigeria with chlorotic rosette disease revealed the presence of the two viruses previously described in association with this disease, GRV and GRAV, and confirmed the report of Hull \& Adams (1968) that GRV depends on GRAV for transmission by Aphis craccivora. The immunoelectron microscopy studies also confirm and extend the report of Casper et al. (1983) that GRAV is a luteovirus, related especially to 
BLRV, BWYV and PLRV. However, in the absence at present of antiserum to GRAV we are not able to determine the closeness of these relationships by the ISEM technique. More limited observations showed that viruses resembling GRV and GRAV are also associated with green rosette disease but suggest that the GRV component may differ from that associated with chlorotic rosette in inducing milder symptoms in some herbaceous hosts. Further work is required to show whether this is true for all isolates from groundnuts with green rosette. The luteovirus associated with green rosette is similar to that associated with chlorotic rosette in that particles of both viruses are trapped efficiently by antiserum to BLRV but we have not made detailed comparisons.

The most useful test plants we found were Chenopodium amaranticolor for local lesion assay, and Nicotiana benthamiana and $N$. clevelandii for virus propagation. Although $C$. amaranticolor did not produce lesions during the winter months under glasshouse conditions in Scotland, suitable conditions could probably be obtained in a controlled environment chamber. The host range studies showed that the virus studied in the present work is essentially the same as that described by Okusanya \& Watson (1966) and Dubern (1980). At the time of Okusanya \& Watson's (1966) work the existence of two viruses in groundnut plants with rosette was not known, although their studies led them to suspect it; however our results indicate that the symptoms they described in non-leguminous hosts were those of GRV alone. The results of further studies on the properties of GRV are presented in the accompanying paper (Reddy et al., 1985).

The use of resistant groundnut varieties is the most important means of combating rosette disease and knowledge of the reaction of resistant lines to both components of the complex is essential. Our first attempts to study this have shown that at least some 'resistant' germplasm lines can be infected with GRV. Further work is much needed to show how these and other lines react to GRAV, GRV-C, GRV-G and perhaps other strains of GRV, transmitted by manual and by aphid inoculation.

We thank Gillian Simpson for valuable assistance.

\section{REFERENCES}

BARNETT, O. W. \& MURANT. A. F. (1970). Host range, properties and purification of raspberry bushy dwarf virus. Annals of Applied Biology 65, 435-449.

CASPER, R., MEYER, S., LESEMANN, D.E., REDDY, D. V. R., RAJESHWARI, R., MISARI. S. M. \&UBbaRAYADU. S. S. (1983). Detection of a luteovirus in groundnut rosette diseased groundnuts (Arachis hypogaea) by enzymelinked immunosorbent assay and immunoelectron microscopy. Phytopathologische Zeitschrift 108, 12-17.

DUBERN. J. (1980). Mechanical and aphid transmission of an Ivory Coast strain of groundnut rosette virus. Phytopathologische Zeitschrift 99, 318-326.

DUNCAN, G. H. ROBERTS, I. M. (1981). Extraction of virus particles from small amounts of material for electron microscope serology. Micron 12, 171-173.

DUNN, D. B. \& HITCHBORN, J. H. (1965). The use of bentonite in the purification of plant viruses. Virology 25, $171-192$.

GIBBons. R. W. (1977). Groundnut rosette virus. In Diseuses, Pests and Weeds in Tropical Crops, pp. 19-21. Eds J. Kranz, H. Schmutterer \& W. Koch. Berlin, Paul Parey, 666 pp.

hAYES. T. R. (1932). Groundnut rosette disease in the Gambia. Tropical Agriculture. Trinidad 9 , 211-217.

HULL. R. ADAMS. A. N. (1968). Groundnut rosette and its assistor virus. Annals of Applied Biology 62, 139-145.

OKUSANYA. B. A. M. WATSON. M. A. (1966). Host range and some properties of groundnut rosette virus. Annals of Applied Biology 58, 377-387.

Redoy, D. v. R., mURANT, A. F., RaschiE, J. H., Mayo, M. A. anSa. O. A. (1985). Properties and partial 
purification of infective material from plants containing groundnut rosette virus. Annals of Applied Biology' 107, 65-78.

ROBERTS. I. M. (1980). A method for providing comparative counts of small particles in electron microscopy. Journal of Microscopy 118, 24I-245.

ROBERTS. I. M. \& HARRISON. B. D. (1979). Detection of potato leafroll and potato mop-top viruses by immunosorbent electron microscopy. Annals of Applied Biology 93, 289-297.

STOREY, H. H. \& BOTTOMLEY, A. M. (1928). The rosette disease of peanuts (Arachis hypogaea L.). Annals of Applied Biology 15, 26-45.

STOREY. H. H. \& RYLAND. A. K. (1955). Transmission of groundnut rosette virus. Annals of Applied Biology 43, 423-432.

STOREY. H. H. \& RYLAND, A. K. (1957). Viruses causing rosette and other diseases in groundnuts. Annals of Applied Biology 45, 318-326.

zimmermann. A. (1907). Über eine Krankheit der Erdnüsse (Arachis hypogaea). Der Pflanzer 3, 129-133.

(Received 29 August 1984)

\section{EXPLANATION OF PLATE}

Fig. 1. Particles of GRAV from a crude extract of an aphid-inoculated groundnut (cv. Robut 33-1) detected by ISEM on grids coated with antiserum to BLRV. Stained with uranyl formate $/ \mathrm{NaOH}$. Bar represents $100 \mathrm{~nm}$.

Fig. 2. Local lesions induced by GRV (C) in Chenopodium amaranticolor.

Fig. 3. Local lesions induced by GRV (C) in $C$. murale.

Fig. 4. Local lesions induced by GRV (C) in C. quinoa.

Fig. 5. Necrotic local lesions induced by GRV (C) in $N$. clevelandii.

Fig. 6. Systemic symptoms induced by GRV (C) in $N$. clevelandii.

Fig. 7. Systemic symptoms induced by GRV (C) in Nicotiana benthamiana. 
J

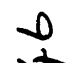

5

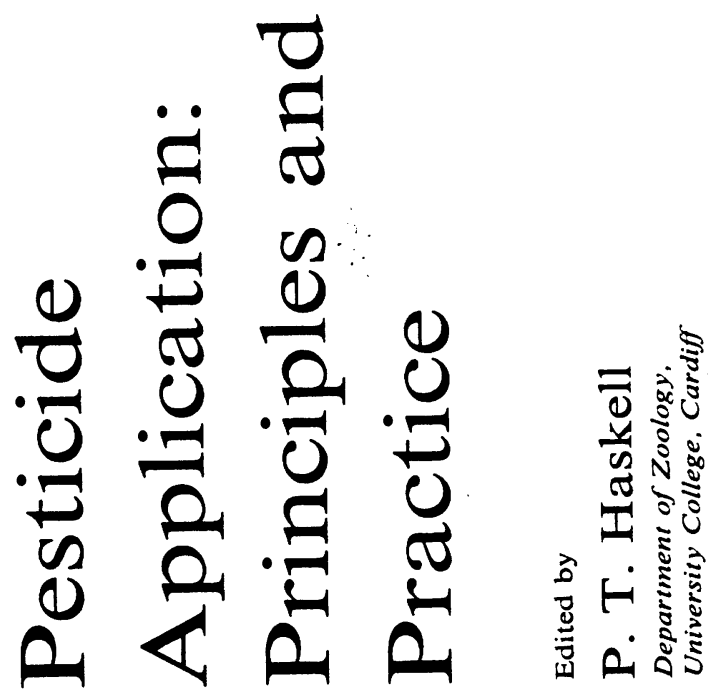

